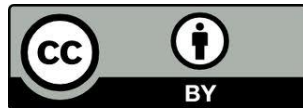

\title{
A RELIGIOSIDADE POPULAR BRASILEIRA
}

\author{
The Brazilian Popular Religiosity
}

\author{
Cátia Cilene Lima Rodrigues \\ Psicóloga, Mestre e Doutora em Ciências da Religião pela PUC-SP \\ catiaclrodrigues@hotmail.com
}

RESUMO: Este trabalho tem por objetivo discutir o campo religioso no Brasil a partir de sua evolução histórica, peculiaridades étnicas, e diversidade de estruturas sociais. A partir da observação do campo valendo-se de estudos descritivos de Gambini, Giddens, Otten, Sanchis, Paiva e Valle, encontramos um cenário marcado pela criatividade da religiosidade popular em parceria com a reflexibilidade da pós moderinidade, que realiza adaptações aos cânones religiosos a fim de se servir da religiosidade de forma prática no cotidiano do crente. Os resultados indicam um emaranhado de concepções simbólicas, conceitos religiosos, tradições culturais, tecidos tal uma colcha de retalhos de diferentes tons e temas, mas que no conjunto faz algum sentido para o ser humano, solitário e desorientado, inseguro no caos urbano e na velocidade da realidade virtual.

Palavras chaves: campo religioso; religiosidade popular; senso religioso; psicologia da religião

ABSTRACT: This paper aims to discuss the religious sphere in Brazil from its historical development, ethnic peculiarities and diversity of social structures. From the observation of the subject making use of descriptive studies of Gambini, Giddens, Otten, Sanchis, Paiva and Valle, find a scenario marked by the creativity of popular religiosity in partnership with the reflectivity of the post moderinidade, which performs adaptations to religious canons to order to serve the religion in a practical way in the believer's daily life. The results indicate a tangle of symbolic concepts, religious concepts, cultural traditions, fabrics such a patchwork of different tones and themes, but which together make any sense to the human being, lonely and disoriented, insecure in the urban chaos and speed virtual reality.

Key words: Religious field; popular religiosity; religious sense; psychology of religion 


\section{Introdução: Campo Religioso Brasileiro: Aspectos Gerais}

O campo religioso contemporâneo no Brasil é marcado pela realidade brasileira de mesclagem entre estruturas sociais pré-modernas, modernas e pós-modernas. Há uma situação de fragmentação religiosa própria do contexto sócio histórico da modernidade brasileira. Contudo, com tantas diferenças, há algo de comum no pano de fundo das religiões populares no país, uma "mínima religiosa".

Para a ciência, o primeiro passo não é a elaboração de uma teoria geral, mas antes, a observação dos fenômenos, em estudos descritivos para, só então, teorizar sobre os mesmos. Sendo uma ciência positiva, e não especulativa, cabe à Psicologia observar fatos, fenômenos, reações, bem como o campo simbólico (antropológico e psicológico), para depois sugerir uma teoria geral sobre o comportamento humano. Sendo assim, e dado o reduzido número de pesquisas de dados empíricos que têm como objeto a religião a partir do prisma psicológico, quero nesse artigo realizar uma análise panorâmica do campo religioso brasileiro, bem como dos procedimentos próprios à Psicologia da religião para compreender mais claramente os elementos envolvidos no que se refere à religiosidade popular.

A Psicologia da Religião no Brasil têm seus primeiros estudos influenciados pela área médico psiquiátrica, no século XIX e início do XX, que considerava as formas de religião popular como transtornos ou patologias mentais. Entre as décadas de 30 e 60 do século passado, o estudo dos fenômenos religiosos no país foi algo de interesse da Antropologia e História, com contribuições significativas em pesquisas produzidas na Universidade de São Paulo. Esses estudos recusavam o uso do termo "religiosidade", considerando que o termo sugeria um caráter subjetivo e impessoal, o que contrariava sua afirmação de que a cultura Brasileira apresenta religiões com caráter messiânico e sincrético. A Teologia da Libertação, com sua abordagem sociológica e política, com forte influência das ideias marxistas, contribui para o mapeamento do campo religioso brasileiro nas décadas de 80 e 90 do século XX. Mas, com o avanço do neoliberalismo globalizador, houve uma fragmentação do campo religioso. A porosidade na qual se encontra o campo do esporte, da política, da economia, dos valores, etc., é a mesma no campo da religião: a crise de valores da modernidade tem também seus reflexos na religião e religiosidade. 
De acordo com Sanchis (1997), subentende-se que há uma religião culta, com teologias e práticas hierárquicas, em organizações superiores; e a religião popular com formas inferiores, da classe baixa, que recebe influência das religiões cultas. Deste modo, falar em religião do povo é a forma do autor de valorizar a religiosidade popular, enquanto protagonista e criativo de religiões organizadas e resistentes à influência da religião não popular, não do povo. Sendo assim, compreende-se que Religião refere-se a um conceito sociológico, com uma construção coletiva, enquanto que Religiosidade remete a uma experiência pessoal e psicossocial.

Com o fenômeno atual da Religiosidade popular crescente nas grandes cidades, o Campo Religioso enquanto objeto de observação se afasta das discussões entre religião e religiosidade, de popular ou do povo, e passa a ter maior interesse da óptica do impacto da globalização sobre as religiões do povo. De acordo com Boff (1998), a religião do povo apresenta sua produção e elementos próprios, mas a hierarquia da Igreja, em seu poder sistemático, se apropria desses elementos e os administra para os manterem em sua hegemonia do poder.

Assim, a expressão atual da religiosidade popular e o campo religioso cristão brasileiro apresentam uma tensão entre grupos mais marxistas e grupos mais carismáticos, com estes últimos em franco crescimento, com resgate da simbologia popular. O movimento carismático ou pentecostal no cristianismo popular brasileiro representa o que há no campo religioso brasileiro atual no quadro da Globalização em termos de mística, racionalização ou experiência individual. É a expressão do encontro dos elementos religiosos da Pré-modernidade, modernidade e pós-modernidade, num mesmo espaço e tempo.

\section{Em que tempo estamos}

A formação da sociedade brasileira apresenta três matizes religiosos fundantes: a religiosidade popular portuguesa, a religiosidade africana, e as raízes indígenas do povo brasileiro que, para a compreensão da constituição da religiosidade popular do país é mais relevante que as contribuições oficiais do catolicismo romano.

Gambini (1988) reflete a questão da identidade brasileira a partir de sua origem anterior às perdas ocorridas durante o processo civilizatório da dominação européia do 
território, evidenciando uma dissociação na consciência e identidade nacional que negligencia seu passado. Fundamentando-se em Darcy Ribeiro, o autor defende que do processo de colonização em que índios, negros e europeus se miscigenaram, surge o povo brasileiro como “... um híbrido que nunca saberá quem é, porque nem pai nem mãe lhe servirão de espelhos ou modelos de identidade" (Gambini, 1988: 22), destituído de alma ancestral.

Neste sentido, afirma que a consciência coletiva brasileira apresenta a ideia de que somos fusão de etnias, mas que despreza ou envergonha-se das contribuições indígenas e negras, apontando a sobreposição de um estilo de consciência e padrão de valores - o europeu - sobre o outro que é negado como se não contivesse valor, detonando um drama oculto na consciência brasileira que não se desenvolve no sentido da alteridade, condição essencial para “... nos completar psíquica e historicamente, quando então descobriríamos a plenitude de nossa verdadeira identidade" (Ibid:: 26).

Na origem da formação cultural do país, há uma acomodação cultural dessas diferentes matizes, produzindo um verdadeiro sincretismo religioso na formação da religiosidade do povo entre 1550 (1554) e 1808. Mas, a partir de 1822 até meados de 1889, ocorre a denominada romanização do Catolicismo, com a separação entre Igreja e Estado no Brasil, a formação dos colégios católicos, a estruturação da Igreja autônoma ligada ao papado, configurando o imperialismo e a hegemonia católica.

A partir de 1939, até os dias atuais, se observa o terceiro tipo de religiosidade popular no país. Com a modernização da economia, da política, da urbanização, a religiosidade passa a ser influenciada também pelos processos de Globalização, sendo marcada por ela, caracterizando o fim do monopólio da Igreja Católica sobre a religiosidade popular e a maior diversidade no campo religioso brasileiro.

Essa diversidade é demarcada pela assimilação do catolicismo popular marcado pela mística e devoção, e transmitido pela própria família - pelo êxodo rural para os grandes centros urbanos, com seu mapa religioso caótico e com grande quantidade de opções de grupos religiosos: solitários, os indivíduos filiam-se a grupos de acolhida, acrescentando símbolos e significados a si. A racionalidade iluminista posta em xeque pela própria modernidade, deixa de convencer ou dar sentido 
existencial às pessoas, que cada vez mais se sentem seguras em agrupamentos religiosos, compõe o quadro.

Para a análise do campo religioso contemporâneo no Brasil, Sanchis (1997) aponta alguns fatores relevantes, como o fim da hegemonia católica, marcada pelo declínio sistemático do número de adeptos desde 1980, a diversidade religiosa, que se multiplica, mesmo dentro do próprio catolicismo, combinando identidades e posições, e a presença simultânea de três etapas da modernidade no Brasil. Para o autor, várias características compõem a complexidade do panorama do campo religioso brasileiro atualmente: a quebra do monopólio de um sistema religioso, o Catolicismo, que além de numérica é qualitativa; a diversidade de elementos, em que as diferenças se acentuam cruzando-se dialeticamente, numa combinação de identidades e modos de adesão religiosa (o recém convertido traz elementos sociais e psicológicos ao novo grupo, configurando um pluralismo religioso); nessa diversidade, surge uma espécie de bricolagem, em que cada sujeito, sozinho, e no contexto de mudanças constantes, vai compondo algo que dê sentido à sua existência, tentando se compreender como pessoa nesta dinâmica caótica e fragmentada.

A religiosidade popular viabiliza a permanência humana na solidão urbana. Há uma sensibilidade nos grupos populares para buscar uma nova forma de vivência da espiritualidade como meio de sentido à existência. Mas essa destradicionalização, adornada pela crise de identidade, reflexividade e individualismo, oferece riscos à sociedade moderna, sobretudo no que se refere à convivência nas grandes cidades (Giddens, 1991). Há uma preocupação com os fundamentalismos, em que a realidade atual busca uma terceira via que seja alternativa para a perspectiva da universalidade absoluta, bem como para o relativismo particular.

De acordo com Sanchis (1997), a religiosidade brasileira apresenta características 1) pré-modernas, com a forte presença do ritual mágico-religioso e de obrigação em relação ao transcendente, 2) modernas, com o ideal do indivíduo com razão única, bem como a construção eclética e 3) radicalmente individual, que caracteriza a pós-modernidade. Para o autor, não há fases, mas a co-existência de "lógicas" diferente em combinação nas situações. 
No contexto social urbano atual, como dito antes, perduram elementos prémodernos, modernos e pós-modernos no jogo de tensões e solidão. Assim, enquanto há exigências de definição da identidade religiosa do indivíduo pelas cúpulas, o povo continua transitando em diversos grupos religiosos. Há um clima de permissividade em tensão com o sectarismo intolerante. Há o "fast food religioso", ou seja, a associação da religiosidade ao marketing, que segue a lógica empresarial moderna. Há a ausência de critérios para a filiação religiosa, resultado da somatória de um campo plural a verdades desconstruídas. Há a preocupação com a subjetividade colocando em dúvida a identidade do indivíduo, e suas opções pessoais. A fragmentação destas identidades, em reflexo da fluidez dessa realidade, provoca a necessidade do auto-conhecimento (reflexividade) diante da crise subjetiva.

Enfim, de acordo com Sanchis (1997), o campo religioso brasileiro se configura a) pela necessidade de recentramento da função simbólica, do imaginário, que fora descentrado pela modernidade; b) por configurar uma operação totalizante, holística, mas não submetida a um eixo centralizador; e c) pela presença de aspirações de um Self indissolúvel, espiritual e corporal, para o sujeito, mas que fica à mercê de procedimentos de auto-ajuda na solidão urbana.

\section{Por minha culpa, minha tão grande culpa}

A religiosidade Brasileira, marcada pelo traço penitencial no cristianismo - de caráter sacrificial, e com necessidade de purgar o pecado - encontra-se, ainda, vinculada à religiosidade familiar, vinculada à cultura familiar, e não às prescrições

oficiais das religiões. É a tradição religiosa consolidada que orienta a religiosidade e a própria conduta pessoal de cada indivíduo.

Herança do catolicismo colonial brasileiro, perdura no imaginário religioso popular, marcado pela realidade sofrida, a concepção da dialética entre o medo e a esperança. De acordo com Otten (1999), a vida extremamente difícil do povo é marcada pela esperança de que o céu se abra e que se receba a misericórdia divina, em que o indivíduo se identifica com a figura mártir presente em Jesus, no calvário, na penitência, na vida dos santos. De fato, o contexto religioso brasileiro ainda é fortemente marcado pela tradição do catolicismo simples e popular, que anseia pela 
fraternidade e felicidade em um cenário em que o perigo do pecado seja diminuído e a vivência cristã de esperança, coerente com a ideia de serviço a Deus, como restaurador da dignidade humana, se concretize pela salvação na realidade social.

Sendo assim, a noção de Deus emerge da angústia existencial gerada em situações de limite da existência humana, como elemento de esperança sobre a situação do medo. De acordo com Valle (1998) e Otten (1999), os seres humanos reagem com semelhança no sentido do medo e esperança, não em continuidade ou equiparação, mas com emoções primitivas e inspiradoras da religiosidade que, então, dialoga com a ciência e com a racionalidade. Deste modo, e de acordo com Jung, não há superioridade nas religiões históricas por sua racionalidade, pois a base de todas elas é o conjunto das mesmas estruturas emocionais, presentes no inconsciente coletivo. Nesta perspectiva, as religiões apresentam algo em comum no que se refere à fé: diante da angústia existencial - seja pela morte, pelo medo, pelo limite - o ser humano tende à inclinação religiosa de caráter messiânico, numa esperança defensiva, em forma de mitos de libertação.

Num cenário político de opressão, constante na realidade brasileira, a presença do messianismo é uma das fortes características da religiosidade popular, enquanto uma alternativa, na ação religiosa, para o sujeito alcançar melhor qualidade de existência. Do prisma psicológico, o medo expressa os elementos arquetípicos sombrios ou recalcados, tornando-se constitutivo para o desenvolvimento do indivíduo no sentido da individuação. Assim, em mitos e sinais do fim, mesmo que desenvolvidos pela mídia em tempos de maior crise, temos a promoção de movimentos religiosos messiânicos de esperança, em busca do caminho de volta ao paraíso.

Numa leitura psicológica do milenarismo brasileiro - considerando a presença de idéias escatológicas sobre um fim eminente, a expectativa por uma mensagem ou unção que encaminhe a direção ao futuro, mitos de retorno ao paraíso, utopia política, e sentimento de batalha espiritual entre o bem e o mal - pode-se observar a impregnação de religiosidade com a presença constante da figura de um messias, o sonho de uma áurea de harmonia universal, e o imaginário popular que concretiza comportamentos que transpõe o tempo. 
Esses comportamentos não se restringem à classe economicamente mais pobre, mas compõe a religiosidade popular como um todo, em que a classe média se inclui na elaboração da cultura do reavivamento religioso, que gera a sensação de segurança diante às incertezas da Pós Modernidade. $\mathrm{O}$ milenarismo configura a reinterpretação de esperanças não verificadas, e decorre do contato entre duas culturas, em que uma é oprimida pela outra, que está presente na tensão entre o fascínio pelo mal e o desejo de sua superação (medo), e poderosas fantasias de abundância (esperança), o que expressa uma necessidade psicológica de proteção maior: o indivíduo canaliza o medo e a esperança numa direção ou proposta simbólica acessível a todos.

De acordo com os teóricos da Pós-Modernidade, esse fenômeno é comum ao campo das religiões no ocidente, em que a dificuldade de ser uma pessoa no mundo mecanicista leva a pessoa a um momento de necessidade religiosa de encontro e relação com o Outro, caracterizando o reavivamento da religiosidade. Não há homogeneidade na perspectiva científica racional, o que leva a pessoa à dúvida e a um "eclipse" da razão, enfrentado pela humanidade contemporânea em geral. Dessa necessidade de superação do vazio, a via da religião surge como possibilidade: é relação e experiência de alteridade, com o outro, rica em elementos de significados subjetivos. Nesse sentido, configura-se uma época de "mergulho" no Sagrado: a crise da racionalidade projeta a experiência sensorial, emocional intuitiva, numa condição gnóstica pela busca de um saber não empírico, mais global, harmônico reintegrador, com espessura simbólica.

\section{A Perspectiva Psico-Social da Religiosidade Popular}

A questão da Religiosidade Popular no Brasil remete a uma questão fundamental para a Psicologia: a elaboração da identidade cultural. Com o conflito de diferentes lógicas - as internas e as externas, como a Globalização - o problema de ser "nós mesmos" em nossa "caboquice" que mescla índio, negro e europeu, a religião adquire um poder simbólico de função política, enquanto transformadora da realidade e agente distribuidor da riqueza. Do mesmo modo, configura fator de integração social, enquanto gerador de sentido pelo conhecimento e comunicação.

Tanto para Weber (1997) como no pensamento Durkheimiano, só se compreende uma sociedade conhecendo a lógica e o núcleo religioso dela, pois suas 
crenças regulam o comportamento do sujeito e, em conseqüência, a dinâmica coletiva. Assim, evidencia-se a importância do estudo da religiosidade popular para compreensão social, bem como para ações de cunho político: a religiosidade popular cria sua identidade religiosa independente da autoridade institucionalizada, vivenciando a religiosidade. Ignorar o poder dos simbolismos religiosos e sua relação com o poder econômico e político é tão ingênuo quanto parece ser interpretar o simbólico: o poder simbólico gera o sentido necessário para a confiança e atribuição de poder na esfera política e econômica concreta, pois a convicção religiosa é o motor da ação.

A subjetividade - que na atualidade assume como traço característico o isolamento e fragmentação do sujeito sem identidade no mundo plural - gera a perda da plausibilidade dos grandes relatos de origem e sentido de vida. Sem pedagogias unificadoras que expliquem tudo, a religião faz sentido nesse emaranhado de conhecimento e informações desconexas, diante a necessidade de refazer a identidade religiosa e de construir a própria lógica simbólica em cada sujeito. Assim, configura-se uma dinâmica de privatização da Religião: o indivíduo constrói, longe da instituição social, sua rede simbólica subjetiva, em que se perde o poder e a importância do grupo social. Há um retorno ao religioso, mas privatizado no mundo ocidental. Associando estes fatores à já mencionada influência do catolicismo colonial popular na religiosidade brasileira, observa-se a presença marcante de uma concepção devocional, protetora e mágica da realidade religiosa, com a presença de símbolos e instrumentos mágicos para selar materialmente a relação com o Sagrado, a noção de entrega à relação com o divino, e a necessidade prática de socorro e auxílio para evitar os perigos profanos do cotidiano. Essas concepções religiosas dão sentido ao sujeito, pois descartam a necessidade de comprovação, sendo evidentes para o indivíduo em sua vida prática, sem distinção entre sagrado e profano.

De acordo com Valle (1997), a religiosidade popular nos contextos urbanos apresenta as funções de promover integração social à pessoa, redefinição da sua personalidade, tratar e cuidar emocionalmente, trazer sentido existencial à vida do indivíduo. Deste modo, a análise da religiosidade popular não se restringe à dimensão doutrinal, mas sobretudo inclui o sistema de representações e atitudes que se relacionam com a realidade social e econômica externa, configurando um processo do indivíduo no grupo - no grupo religioso, no lugar popular, com imaginário religioso 
próprio do grupo popular urbano moderno, com suas características e estratégias próprias, com dinâmicas e relacionamentos específicos. Nas diferentes religiões surgem, então, novas relações específicas, mas atualmente com uma constante: a da privatização, fragmentação dos valores e conceitos, da bricolagem de crenças.

Ao configurar núcleo de comunicação, de símbolos, significados e valores, a religião constitui uma comunidade emocional de fraternidade e relacionamento em que há segurança e dignidade na união, tanto em nível primário, experiencial e pessoal, como em nível secundário, burocratizado e massificado (Weber, 1997). O problema urbano contemporâneo da cultura de massa e da necessidade do sujeito desenvolver relações individuais significativas soma-se, no campo religioso brasileiro, ao fenômeno da múltipla origem cultural que compõe a identidade nacional. Assim, a urbanização recente e a ampla imigração completam a caracterização do fértil campo para o aparecimento e multiplicação de uma religiosidade popular de relacionamento primário: da solidão e impessoalidade da realidade, e do campo religioso brasileiro em complexo emaranhado de dinâmicas histórico-sociais que moldam os elementos e o perfil da religiosidade atualmente.

\section{Considerações Finais}

Por fim, não é possível compreender religião e religiosidade sem compreender a cultura e a natureza humana (seus aspectos evolutivos e genéticos). A compreensão do fenômeno religioso é imprescindível para a elaboração da integração bio-afetivo-social, pois sua elaboração promove condições afetivas, cognitivas, físicas para o indivíduo viver melhor. E, mesmo com a presença da diversidade cultural, a religião, em geral, trabalha o amor e a tolerância, que determinam comportamentos essenciais para a sobrevivência da humanidade. $\mathrm{O}$ ideal de sobrevivência, somado à esperança diante do limite da existência, resulta na interiorização do Transcendente. Sendo essa relação impossível de ser verbalizada em sua totalidade, evidencia-se a importância da análise dos símbolos: função útil para a compreensão da religiosidade popular. Assim, passaremos a discutir a presença do cristianismo e a noção da verdade para experiência gestacional especificamente na realidade da mulher contemporânea que vive em grandes centros urbanos. 
Podemos observar que o campo religioso contemporâneo define-se por um emaranhado de concepções simbólicas, conceitos religiosos, tradições culturais, tecidos tal uma colcha de retalhos de diferentes tons e temas, mas que no conjunto faz algum sentido para o ser humano, solitário e desorientado, inseguro no caos urbano e na velocidade da realidade virtual.

\section{Referências Bibliográficas}

ABBAGNANO, Nicola. Dicionário de filosofia. São Paulo: Martins Fontes, 2000.

ALMEIDA, A. M.; LOTUFO NETO, F. Diretrizes metodológicas para investigar estados alterados de consciência e experiência anômalas, Revista de Psiquiatria Clínica, São Paulo, n. 1, v. 30, p. 21-28, 2003.

ALVES, Rubem. O que é Religião. 17ª ed. São Paulo: Brasiliense, 1994.

ALLPORT, G. The Individual and his Religion. Chicago: Chicago University Press, 1950.

AMARAL, M.J.C. A Natureza Religiosa da Religião e a Natureza Psicológica da Psique: a psicologia profunda aponta para essa afinidade, Último Andar, São Paulo, ano 8, n.12, 2005.

ARMSTRONG, K. Uma História de Deus: quatro milênios de busca do Judaísmo, Cristianismo e Islamismo. São Paulo: Companhia das Letras, 2002.

AVILA, A. Para Conhecer a Psicologia da Religião. São Paulo: Loyola, 2007.

AZEVEDO, A. C. M. A vivência religiosa como processo de transformação pessoal. Cogeae-PUCSP: São Paulo, 2006. (Monografia)

BAUDRILLARD, Jean. A Troca Impossível. São Paulo: Nova Fronteira, 2002.

À Sombra das Maiorias Silenciosas. O Fim do Social e o Surgimento das Massas. 4a . ed. São Paulo: Brasiliense. 1994.

Simulacro e Simulação. Lisboa: ed. Relógio D’Água, 1991. 
BERGER, Peter L.; LUCKMANN, Thomas. A Construção Social da Realidade. Petrópolis: Vozes, 1985.

BIRMAN, Patrícia. Fazendo estilo criando gêneros - Possessão e diferença de gênero em terreiros de Umbanda e Candomblé no Rio de Janeiro. Rio de Janeiro: UERJ, 1995.

BRANDÃO, Carlos Rodrigues. Ser católico: dimensões brasileiras; um estudo sobre a atribuição através da religião. In: SANCHIS, Viola et al. Brasil \& USA: Religião e Identidade Nacional, Rio de Janeiro: Graal, 1998, p. 27-58.

CAIRNS, E. E. O Cristianismo através dos séculos: uma história da igreja cristã. 2 ed. São Paulo: Vida Nova, 1995.

CATALAN, Jean-François. O Homem e sua Religião: enfoque psicológico. São Paulo: Paulinas, 1999.

CAVAlCANTI, Tito R. A. A Psicologia da Religião de Carl Gustav Jung e a Abordagem Religiosa de Mircea Eliade: Acertos e Desacertos de uma leitura Psicológica dos símbolos Religiosos, 1998. 119 p. Dissertação (Mestrado em Ciências da Religião) PUC. São Paulo.

CONNOR, Steven. Cultura Pós-Moderna. Introdução às Teorias do Contemporâneo. $2^{\mathrm{a}}$ ed. São Paulo: Loyola, 1993.

CROATTO, José Severino. As linguagens da experiência religiosa. Uma introdução à fenomenologia da religião. São Paulo: Paulinas, 2001.

DÁQUILI, E. G.; NEWBERG, A. B. The mystical mind: probing the biology of religious experience. Minneapolis: Fortress Press, 1999.

DELUMEU, J. De religiões e de Homens. São Paulo: Loyola, s.d.

DERRIDA, Jacques e VATTIMO, Gianni (Org.). A religião. O seminário de Capri. São Paulo: ed. Estação Liberdade, 2000. Margens da Filosofia. Campinas: ed. Papirus, 1991.

ESPÍN, Orlando O. A Fé do Povo: reflexões sobre o catolicismo popular. São Paulo: Paulinas, 2000.

FILORAMO, Giovanni; PRANDI, Carlo. As ciências das Religiões. São Paulo: Paulus, 1999. 
GAMBINI, R. Espelho índio: A formação da alma brasileira. Rio de Janeiro: Espaço e Tempo, 1988.

GIDDENS, Antony. Modernidade e Identidade. Rio de Janeiro: Jorge Zahar, 2002. A Transformação da Intimidade: Sexualidade, Amor e Erotismo nas sociedades Modernas. São Paulo: Editora da Universidade Estadual Paulista, 1993. As conseqüências da modernidade. São Paulo: Unesp, 1991.

GOMES, A. M. A. As representações sociais e o estudo do fenômeno do campo religioso.

GROM, B. Psicologia de la Religión. Barcelona: Herder, 1994.

GUERRIÈRE, D. Phenomenology of the Truth Proper to Religion. Albany: SUNY, 1990.

HAMILTON, Malcolm B. The Sociology of Religion. Theoretical and Comparative Perspectives. London-New York: Routledge, 1999.

HARDY, Sir Alister Clavering. The Spiritual Nature of Man: A Study of Contemporary Religious Experience. Oxford: Unknown, 1979.

HICK, J. Truth and dialogue in world religions: confliting truth - daims. Philadelphia: The Westminster Press, 1974.

HILL, P. C.; HOOD Jr., R.W. Measures of Religiosity. Birmingham, Alabama: Religious Education Press, 1999.

JEREZ, Luciana Maria Rezende. A Religiosidade Como Metamorfose Em Busca Da Plenitude: Um Estudo sobre o processo de construção da identidade de noviços franciscano, 1995. 159 p. Dissertação (Mestrado em Psicologia Social) PUC. São Paulo. JAMES, William. The Varieties of Religious Experience. Cambridge-Massachussets: Harvard University Press, 1985.

JUNG, Carl G. O Homem e seus Símbolos. 16a . imp. Rio de Janeiro: Nova Fronteira, 1998.

Psicologia e Religião . 6ª ed. Petrópolis: Vozes, 1987.

O Símbolo da Transformação na Missa. Petrópolis: Vozes, 1985. 
LUCCHETTI, Maria Clara. A Mística Cristã em Reciprocidade e Diálogo: A mística católica e o desafio inter-religioso. In: Teixeira, F. No limiar do mistério: Mística e Religião. São Paulo: Paulinas, 2002.

MACHADO, Maria das Dores Campos Machado. Carismáticos e Pentecostais: Adesão religiosa na esfera familiar. Campinas-São Paulo: Autores Associados-ANPOCS, 1996.

MALDONADO, L. Los datos de um problema. Aproximación inicial. In: MALDONADO, L. Para Compreender el catolicismo popular. Estella: Editorial Verbo Divino, 1990, p. 9-18.

MARDONES, J. M. Adonde va la religión? Cristianismo y religión en nuestro tiempo. Santander: Editorial Sal Terrae, 1996.

MOREIRA-ALMEIDA, A.; LOTUFO NETO, F.; KOENIG, H. Religiouness and mental health: a review. Revista Brasileira de Psiquiatria. 2006.

NUNES, M.J.F.R. Women, Family and Catholicism in Brazil: The Issue of Power. In: Sharon K. Houseknecht and Jerry G. Panhurst. (Org.). Religion and Social Change in Diverse Societies. New York: Oxford University Press, 2000, p. 347-362.

OTTEN, A. Deus é Brasileiro. Uma leitura teológica do catolicismo popular tradicional. Vida pastoral, São Paulo, s.n., p. 13-23, nov-dez. 1999.

OTTO, Rudolf. O Sagrado. Lisboa: Edições 70, 1992.

PAIVA, G.J. Religião, enfrentamento e cura: perspectivas psicológicas. Estudos de Psicologia (Campinas), v. 24, p. 99-104, 2007.

Espiritualidade na Psicologia e Psicologia na Espiritualidade. MAGIS

Cadernos de Fé e Cultura, Rio de Janeiro, v. 47, p. 09-20, 2005.

QUEIROZ, José J. Deus e Crenças Religiosas no Discurso Filosófico Pós-Moderno: Linguagem e Religião. Revista de Estudos da Religião. n² 2, p. 1-23, 2006. (org.). A religiosidade do Povo. São Paulo: Paulinas, 1984.

RODRIGUES, Cátia C. L. Católicas e femininas: processos e metamorfoses na formação da identidade sexual e religiosa de mulheres modernas. 2003. 164 p. Dissertação (Mestrado em Ciências da Religião) PUC. São Paulo. 
RYAN, Penelope J. Católico Praticante: a busca de um catolicismo para o terceiro milênio. São Paulo: Loyola, 1999.

SANCHIS, P. O Campo Religioso será ainda hoje o Campo das Religiões? In: HOORNAERT, E. A história da Igreja na América latina e no Caribe: 1945 - 1995 - o debate metodológico. Petrópolis: Vozes, 1997.

TEIXEIRA, F. (org) A(s) Ciência (s) da Religião no Brasil: afirmação de uma área acadêmica. São Paulo: Paulinas, 2001.

TRIAS, Eugenio. Pensar a Religião. O Símbolo e o Sagrado, In: DERRIDA, Jacques e VATTIMO, Gianni. A religião. São Paulo: Estação Liberdade, 2000, p.109-124.

USARSKI, F. Constituintes da Ciência da Religião: cinco ensaios em prol de uma disciplina autônoma. São Paulo: Paulinas, 2006.

VALLE, E. Sexualidade humana e experiências religiosas. Estudos de Religião, v. 30, p. 66-84, 2006

. Neurociências e religião: interfaces. Rever Revista Eletrônica de Estudos da Religião Puc Sp, São Paulo, n. 3, 2001.

Ano 2000 e milenarismo brasileiro. Vida Pastoral, v. XL, n. 206, p. 2-7, 1999.

. Psicologia e Experiência Religiosa. São Paulo: Loyola, 1998.

- Medo e Esperança: uma leitura psicossociológica do milenarismo brasileiro. Espaços, São Paulo, n. 2, v. 6, p. 109-121, 1998.

VATTIMO, G. O Fim da Modernidade: niilismo e hermenêutica na cultura pósmoderna. São Paulo: Martins Fontes, 1996.

VERGote, A.; GISEL, P.; TÉTAZ, J. M. (ed.) Théories de la Religion. Lausanne: Labor et Fides, 2002.

Experience of the divine, experience of god. Amsterdã: Leuven

Univerty Press, 1998

WEBER, Max. A Ética Protestante e o Espírito do Capitalismo. 12 ${ }^{\mathrm{a}}$ ed. São Paulo: Pioneira, 1997. 
Rejeições Religiosas do Mundo e suas Direções. In: Max Weber. Col.

Os Pensadores. $2^{\mathrm{a}}$ ed. São Paulo: Abril Cultural, 1980, p. 237-268.

WEISS, Rosa Amélia Almeida. Trânsito Religioso no Brasil: a múltipla pertença de mulheres católicas em São José dos Campos, 2002. 220 p. Dissertação (Mestrado em Ciências da Religião) PUC. São Paulo.

WOODHEAD, Linda. Religions in the Modern World: Traditions and Transformations

- Women and gender: a theorical framework. London/New York: Routledge, 2002.

Recebido: 05/07/2015

Received: 07/05/2015

Aprovado: 13/07/2015

Approved: 07/13/2015 